\title{
PCR Buffer Optimization with Uniform Temperature Regimen to Facilitate Automation
}

\author{
M.M. Blanchard, P. Taillon-Miller, P. Nowotny, and V. Nowotny
}

Washington University School of Medicine, Center for Genetics in Medicine, St. Louis, Missouri 63110

\begin{abstract}
To facilitate $P C R^{(1,2)}$ reactions in large numbers with uniform conditions, the annealing temperature was fixed and the stringency of the reactions was adjusted by optimizing the ion conditions of the reaction. The buffer system is based primarily on Tris ( $T$ ), ammonium ( $N$ ), and potassium $(K)$ to adapt assay conditions to different primer pairs. The TNK buffers have permitted successful screening of a 60,000 -clone yeast artificial chromosome (YAC) library with more than 200 primer pairs.
\end{abstract}

hysical mapping of the genome is a part of the process to reach the complete sequence analysis of human DNA. Primer pairs and the PCR products they define, sequence tagged sites (STS), ${ }^{(3)}$ serve as ordered landmarks along the DNA, and coverage of the genome with about one STS every $100 \mathrm{~kb}$ (or 30,000 in all) is envisaged.

In the formulation of STS content mapping, STSs are used to find cognate yeast artificial chromosomes (YACs) ${ }^{(4)}$ by recursive screening of a library of YAC clones. The YACs are then overlapped by their common content of STSs. In practice, libraries of thousands of YACs are stored in 96-well microtiter arrays, and screening with a single STS involves nearly 200 PCR assays to find five positive clones. The numbers of STSs and PCR reactions thus require efficient generation of STSs and reliable screening.

Programs have been designed that infer usable primer pairs for STSs from tracts of relatively unique sequences on the order of 200 bp long. ${ }^{(5)}$ Two problems have been encountered, however. First, although large numbers of PCR primers are studied at many locations, the parameters that determine the performance characteristics of a particular primer pair have not been completely clear. In particular, the numbers and intensities of extraneous reaction products are hard to anticipate - probably because they depend on the poorly known relative frequencies of various sequences in genomic DNA. Second, the conditions used to optimize signal to noise often vary considerably for different primer pairs, and this makes it very difficult to standardize or automate the screening of a number of STSs at the same time.
One way to provide adequate discrimination of a true product compared to the background is to manipulate the ratio of signal to noise. Frequently, temperature is varied to favor the authentic product. But variable temperatures for different primer pairs, like variable time intervals or cycle numbers, obviously complicate bulk screening. In contrast, universal temperature conditions would permit many different primer pairs to be assayed at the same time and could point toward automated procedures. Here we describe such a regimen, which optimizes PCR conditions by varying ion concentrations rather than temperatures.

\section{MATERIALS AND METHODS Temperature Conditions}

All PCR assays were done in a PerkinElmer Cetus DNA Thermal Cycler. Samples were first preheated for $2 \mathrm{~min}$ at $94^{\circ} \mathrm{C}$ to melt the template DNA. Then 35 cycles proceeded for $1 \mathrm{~min}$ at $94^{\circ} \mathrm{C}, 2$ $\min$ at $55^{\circ} \mathrm{C}$, and 2 min at $72^{\circ} \mathrm{C}$. The run was terminated at $72^{\circ} \mathrm{C}$ for $4 \mathrm{~min}$ and the temperature was then reduced to $4^{\circ} \mathrm{C}$ for sample storage until further processing.

\section{Assay Conditions}

Reagents and conditions are described in Results. In general we used $0.5-\mathrm{ml}$ GeneAmp Reaction tubes (Perkin-Elmer Cetus N801-0180) with 5- $\mu$ l assay volumes. Each sample was overlaid with $20 \mu \mathrm{l}$ of mineral oil (Sigma M-5904) to reduce condensation. The assays were prepared from a set of stock solutions: Taq polymerase ( 5 units $/ \mu$ l; Perkin-Elmer Cetus N801-0060, 0.5 units/assay); and $2.5 \mathrm{~mm}$ 
dNTPs made from their sodium salts (Boehringer Mannheim 103 985, 104 043, 104 108, 104272 ) and then adjusted to $\mathrm{pH} 7.5$ at room temperature with unbuffered $30 \mathrm{~mm}$ Tris (Boehringer Mannheim 604 205). DNA (33 - $100 \mathrm{ng}$ ). Primer pairs $(5 \mu \mathrm{M})$ were stored in sterile bidistilled water. If not stated otherwise, the tested primer pairs produced either a 380-bp double-stranded DNA fragment from the $\beta$-globin locus (BG 380) or a 200-bp product from the HLA locus (HLA 200). The four oligonucleotides were 20 -mers.

\section{TNK Buffers}

TNK25,10× (100 mM Tris-HCl, pH 8.3; 50 $\mathrm{mM} \mathrm{NH}_{4} \mathrm{Cl} ; 250 \mathrm{~mm} \mathrm{KCl} ; 15 \mathrm{~mm} \mathrm{MgCl}_{2}$ ); TNK50,10× (100 mM Tris-HCl, pH 8.3; 50 mм NH${ }_{4} \mathrm{Cl} ; 500 \mathrm{~mm} \mathrm{KCl} ; 15 \mathrm{mM} \mathrm{MgCl}_{2}$ ); TNK100,10× (100 mм Tris- $\mathrm{HCl}, \mathrm{pH} 8.3$; $50 \mathrm{mM} \mathrm{NH} \mathrm{Cl}_{4}$; $1 \mathrm{M} \mathrm{KCl} ; 15 \mathrm{~mm} \mathrm{MgCl}_{2}$ ).

Additional buffers in the TNK series were prepared with augmented magnesium concentrations (containing as $10 \times$ buffers $30 \mathrm{mM} \mathrm{MgCl}_{2}$ or $45 \mathrm{mM} \mathrm{MgCl}_{2}$, respectively, resulting in final magnesium concentrations of $1.5,3.0$, and 4.5 $\mathrm{mM} \mathrm{Mg}^{+2}$ in the assays). The buffers were prepared from stock solutions: $1 \mathrm{M}$ Tris- $\mathrm{HCl}, 1 \mathrm{M} \mathrm{NH}_{4} \mathrm{Cl}, 1 \mathrm{M} \mathrm{MgCl}_{2}$, and $2 \mathrm{M}$ $\mathrm{KCl}$. No special precautions seemed necessary to ensure the integrity of the buffers over time, because none of the buffer components is subject to decomposition. The buffers were prepared in 1-liter quantities and kept either refrigerated $\left(4^{\circ} \mathrm{C}\right)$ or frozen at $-20^{\circ} \mathrm{C}$ in small individual aliquots, with no loss of performance over time. In addition, we tested buffers kept at room temperature for more than 1 year and found no reduction in product quality.

\section{Product Determination}

After completion of the PCR, $2 \mu$ l of dye was added to each sample $(0.25 \% \mathrm{wt} / \mathrm{vol}$ bromophenol blue, $0.25 \% \mathrm{wt} / \mathrm{vol}$ xylene cyanole, $30 \% \mathrm{vol} / \mathrm{vol}$ glycerol in water). The mixture was applied to a dry well of a polyacrylamide gel (10\% acrylamide and $15 \%$ glycerol). After all gel lanes were loaded, running buffer $(1 \times \mathrm{TBE})$ was overlaid to fill the wells completely. The gel apparatus (BIORAD Mini-PROTEAN II) was assembled, and electrophoresis was carried out for $2.5 \mathrm{hr}$ at 90 V. Gels were stained with $0.01 \%$ ethidium bromide solution for $10 \mathrm{~min}$. Excess ethidium bromide was removed by one subsequent water wash for 20 min with gentle shaking. The gels were analyzed and photographed on a Fotodyne Foto/ Prep I system.

\section{RESULTS}

PCR conditions were sought that meet simple standards: (1) fixed temperature and cycling parameters for PCR assays in library screenings; and (2) easy identification of product bands, with minimal background from yeast or extraneous human DNA species. Unless otherwise indicated, all assays were run at the TNK cycling conditions mentioned earlier.

\section{Effects of Divalent Cations}

\section{$\mathrm{Mg}^{2+} / \mathrm{dNTP}$ Titration}

The bivalent magnesium ion binds tightly to the phosphate sugar backbone of nucleotides and nucleic acids. Thus, its variation has strong and complex effects on experiments involving nucleic acid interactions. To examine the effect of magnesium on PCR, its concentration was varied between $0.25 \mathrm{~mm}$ and $5 \mathrm{~mm}$. dNTP concentrations were also varied (from 100 to $3200 \mu \mathrm{M}$ ). Figure 1a shows results for the primer pair HLA200 whereas the results shown in Figure $1 \mathrm{~b}$ were done with BG380. At $0.25 \mathrm{~mm}$ a)
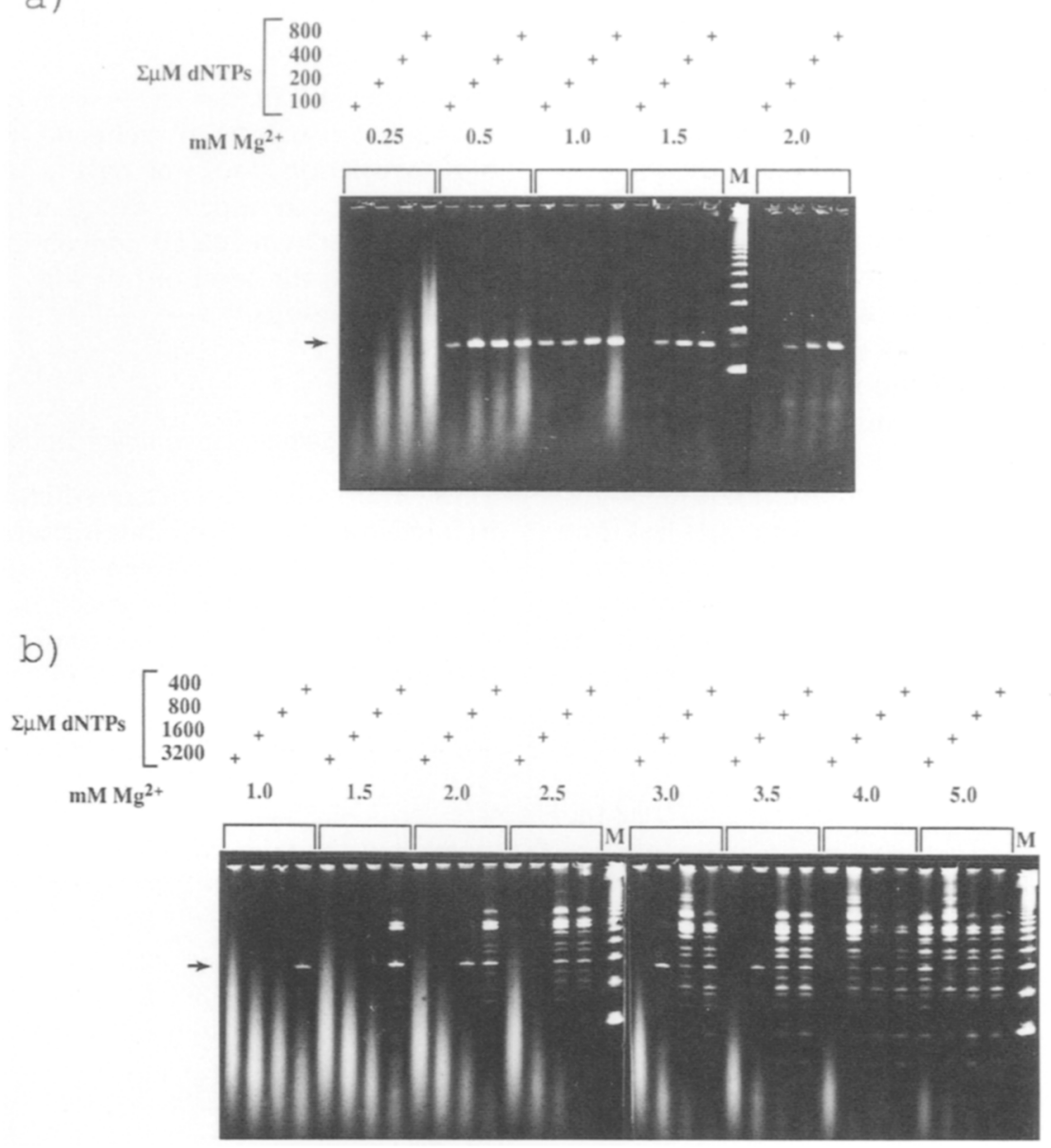

FIGURE 1 Effect of magnesium ion and nucleotide triphosphate variation on PCR product formation. The magnesium concentration and total dNTP concentrations tested in the PCR are indicated. dNTPS were added in equimolar amounts. The marker lane $(M)$ shows a 123-bp ladder as molecular size standard. The other ion conditions were $10 \mathrm{~mm}$ Tris $\mathrm{HCl}(\mathrm{pH} 8.3), 50 \mathrm{~mm} \mathrm{KCl}$. The arrows indicate the correct product size. (a) The primer pair for HLA-200 was added to $0.1 \mathrm{ng}$ of DNA from HY1A (a cognate YAC) and 200 ng of DNA from AB1380 (host strain) as template. (b) The primer pair for BG380 used for this test was HLA 200 with $0.1 \mathrm{ng}$ of DNA from A201F4 (clone with the respective YAC) and $234 \mathrm{ng}$ of DNA from AB1380 (host strain) as template. The arrows indicate the correct product sizes. 


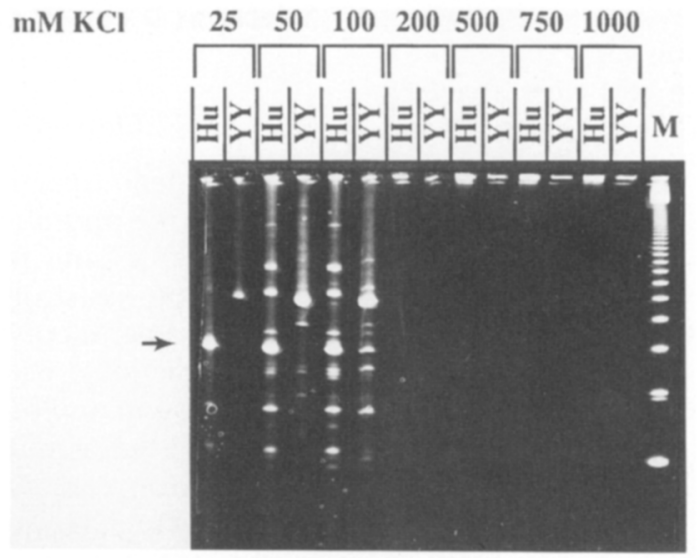

FIGURE 2 Effect of potassium chloride variation on BG380 PCR product formation. The potassium chloride concentration in the PCR was varied between $25 \mathrm{~mm}$ and $1 \mathrm{M}$ as indicated. The template DNA included either $33 \mathrm{ng}$ of total human DNA ( $\mathrm{Hu})$ or $33 \mathrm{ng}$ of DNA from yeast strain $\mathrm{AB} 1380$ (YY). The other ion conditions were $10 \mathrm{mM}$ Tris $\mathrm{HCl}(\mathrm{pH} 8.3), 1.5 \mathrm{mM} \mathrm{MgCl}$. The arrow indicates the correct product size. The marker lane $\mathrm{M}$ shows a 123-bp ladder as molecular size standard.

$\mathrm{Mg}^{2+}$, the reaction failed to produce the expected product. Specificity was maintained at higher levels, but the yield of product could be increased by optimizing the concentration of nucleotides at lower levels (see results at $0.5 \mathrm{mM} \mathrm{Mg}^{2+}$ ).

These results probably reflect the free magnesium concentration in the reaction. [To a first approximation, the free $\mathrm{Mg}^{2+}$ concentration can be taken as total $\mathrm{Mg}^{2+}$ added less the dNTPs, neglecting the minute amount of DNA (230 ng) in the 5- $\mu$ l reaction volume.] At less than $1 \mathrm{mM} \mathrm{Mg}^{2+}$, the expected cognate product band is at its highest concentration, and few extraneous product bands are seen. By $2 \mathrm{~mm}$, other products appear in- creasingly, and higher levels seem to inhibit the reaction in general. Thus, $\mathrm{Mg}^{2+}$ variation does not have a linear effect, but it can improve assays at levels below $4 \mathrm{~mm}$. The dNTP concentration also changes the level of free $\mathrm{Mg}^{2+}$, affecting the results.

\section{$\mathrm{Mn}^{2+}$ and Spermine/Spermidine Titration}

These multivalent cations are often used in nucleic acid reactions, but manganese ion concentrations between 0.5 and 5 mM severely inhibited the reaction and spermine or spermidine concentrations between 0.5 and $3 \mathrm{~mm}$ had no effect (data not shown). Thus, these cations were excluded from reaction mixes.

\section{Effects of Monovalent Cations}

\section{KCl Titration}

$\mathrm{KCl}$ concentration had a great effect on the specficity and yield of the reactions. The concentration was tested up to $1 \mathrm{M}$ (see Fig. 2). At concentrations increasing from 25 to $100 \mathrm{~mm}$, the apparent stringency of the reaction was lessened; with many extraneous product bands evident at $100 \mathrm{~mm} \mathrm{KCl}$ compared to the single band in the human lane at $25 \mathrm{~mm} \mathrm{KCl}$. Above $100 \mathrm{~mm} \mathrm{KCl}$, the reaction was completely inhibited.

\section{$\mathrm{KCl} / \mathrm{NH}_{4}$ Titration}

In several biological systems, potassium and ammonium, which have about the same ion radius, are interchangeable. This has not been true, however, for PCR. Higher potassium levels (see Fig. 3) lower the stringency of the reaction, with more and more extraneous bands appearing. But higher ammonium levels had an opposite effect: stringency was increased, even at relatively low levels. At concentrations of $50 \mathrm{~mm}$ and above, even the yield of the expected product band becomes inadequate. In further experiments (not shown), the effects of the ions on the overall reaction and stringency were balanced to produce the current group of TNK buffers.

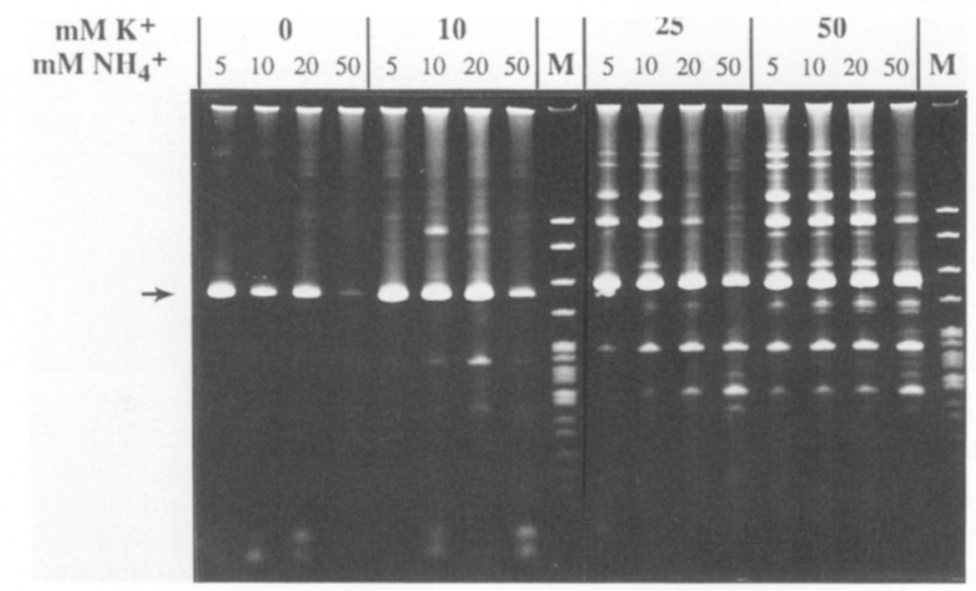

FIGURE 3 Effect of $\mathrm{KCl} / \mathrm{NH}_{4} \mathrm{Cl}$ variation on BG380 PCR product formation. Potassium and ammonium concentration in the PCR were as indicated. The other ion conditions were $10 \mathrm{~mm}$ Tris $\mathrm{HCl}(\mathrm{pH} 8.3), 1.5 \mathrm{mM} \mathrm{MgCl}_{2}$. An arrow indicates the correct product size. The molecular size standard lanes $\mathrm{M}$ show an MspII digest of pBR322. A total $100 \mathrm{ng}$ of total human DNA was added as template. 


\section{Other Reaction Components}

\section{pH Variation}

Values between 6.5 and 9.2 were examined, in steps of $0.5 \mathrm{pH}$ between $\mathrm{pH} 6$ and $\mathrm{pH} 8$, and at additional values of 8.3 , 8.6, 9.0, and 9.2 (measured in assay conditions at $25^{\circ} \mathrm{C}$ ). As exemplified for three different primer pairs in Fig. 4, the reaction yield falls precipitously below $\mathrm{pH} 8$. Yield increases toward higher $\mathrm{pH}$ up to 9.2 , but additional products become visible, suggesting that the stringency of the reaction is reduced. $\mathrm{pH} 8.3-8.6$ was inferred to be optimal, with $\mathrm{pH} 8.6$ giving slightly stronger reactions in some cases, but with more background.

Increases in buffer concentration also lowered the specificity of the reaction and tended to lower the yield of the expected product band, with extraneous products observed both with Tris $\cdot \mathrm{HCl}$ and with $\mathrm{KH}_{2} \mathrm{PO}_{4}$ (data not shown).

\section{Other Additives}

$\mathrm{BSA}$, gelatin, $\mathrm{D}_{2} \mathrm{O}$, glycerol, and polyethylene glycol were tested to see if they improve the behavior of the PCR experiments by protecting the Taq polymerase from premature decay. No significant improvement was found (data not shown), and these agents were left out of PCR assays. (Perkin-Elmer Cetus has also dropped the earlier addition of gelatin from PCR buffer formulations.)

\section{Template-DNA Samples}

DNA solutions kept at $4^{\circ} \mathrm{C}$ for more than 12 months functioned in PCR without significant loss of performance (data not shown). This facilitates multiple reactions without the necessity of thawing the DNA samples each time. To minimize water evaporation, samples were stored in 96-well microtiter trays overlaid with $40 \mu \mathrm{l}$ of mineral oil.

\section{Primer Pair Optimization with TNK Buffers}

Over 200 primer pairs have been optimized with the TNK buffers. For these optimizations, it proved sufficient to use a constant magnesium concentration of $1.5 \mathrm{~mm}$ with the buffers TNK-25, TNK-50, and TNK-100. In $71 \%$ of the cases, the order of stringency was as expected

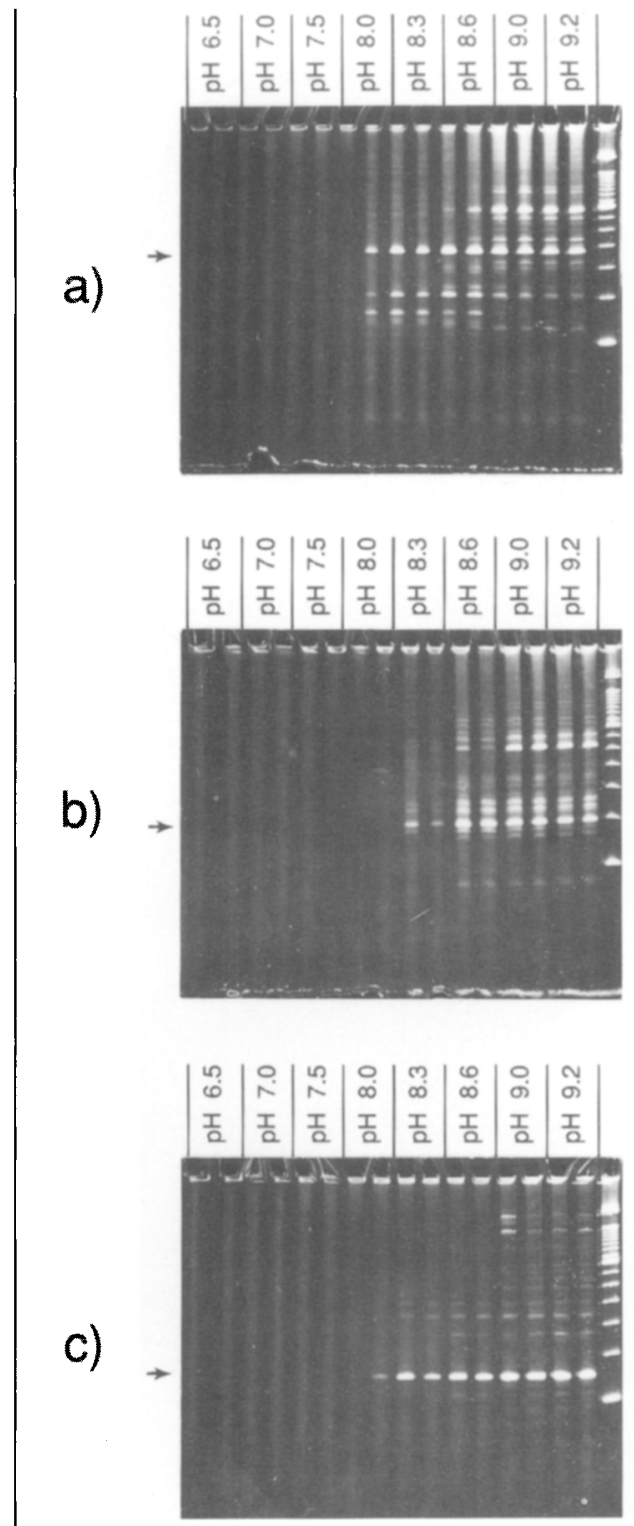

FIGURE 4 Effect of $\mathrm{pH}$ variation on PCR product formation. The indicated $\mathrm{pH}$ values were adjusted with Tris $\cdot \mathrm{HCl}$ at $4^{\circ} \mathrm{C}$. A total of $33 \mathrm{ng}$ of total human DNA was used as template DNA with each of the three primer pairs. The right lane in each panel shows the 100-bp ladder used as molecular size standard. The primer pairs used for this test were: (a) BG380 yielding a 380-bp product band, (b) HLA200 with a 200-bp product, and (c) PRN145 with a 145 -bp product. The other ion conditions were $10 \mathrm{~mm}$ Tris $\mathrm{HCl}(\mathrm{pH} 8.3$ ), $50 \mathrm{mM} \mathrm{KCl}, 5$ $\mathrm{mM} \mathrm{NH}_{4} \mathrm{Cl}$. Arrows indicate the correct product sizes.

above, with TNK-25 the most stringent, then TNK-50, and then TNK-100 (see examples in Fig. 5A-F). For $20 \%$ of the primer pairs, however, TNK-25 and TNK100 showed comparable results, and TNK-50 showed lower stringency (three examples shown in Figure 5G-I; see Discussion).

\section{DISCUSSION}

\section{Concentration Effects}

Although the reactions occurring during PCR are most likely nonequilibrium in nature, as a first approximation there are two equilibria involved (Fig. 6). The first is a standard Michaelis-Menton process discriminating the correct DNA (DNA ${ }_{c}$ ) from the noncognate competitors $\left(\mathrm{DNA}_{\mathrm{n}}\right)$. The second is virtually irreversible, driven by the cleavage of diphosphate from dNTPs.

These considerations affect the critical first round of PCR, even before the amplification starts. The discrimination between cognate and noncognate primer-oligonucleotide template interactions at this step determines the numbers and contributions of extraneous bands. A change in the concentrations of either template DNA or primer pair will obviously affect the primary selection step of primer annealing; but the reaction scheme also indicates the influence of other components. Any change (such as an increase in either dNTP or polymerase concentration) that removes the template* primer complex rapidly from the equilibration process would lessen the discrimination in the first reaction. The effects of changes of primer concentration or polymerase concentration support the above scheme. A reduction in primer concentration or polymerase concentration, however, also reduces the overall yield of the reaction and thus is not the best way to influence the stringency. An increase of both these ingredients on the other hand can get rather expensive and increases in the primer pair can lead to an increase in extraneous bands.

\section{Control of Stringency by lon Concentrations}

Particularly where large numbers of samples are to be handled, a simple approach to provide a robust PCR experiment is essential. Monovalent and divalent cation concentrations provide a means to control the stringency of the reaction, with a $\mathrm{pH}$ of $8.3-8.6$, using TRIS without added gelatin or BSA.

Stringency generally falls sharply with an increasing $\mathrm{KCl}$ concentration up to a range inhibitory for the PCR $(>0.2$ 

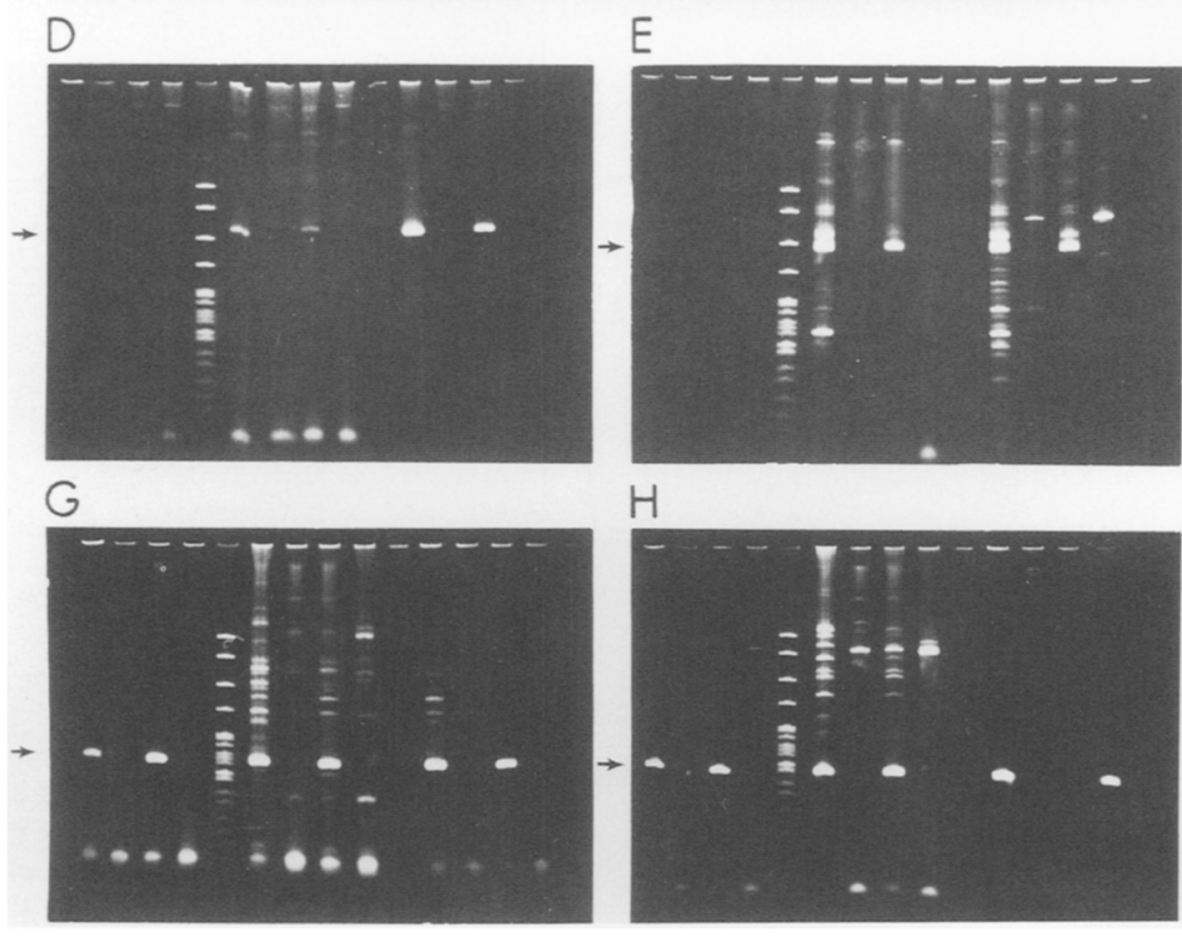

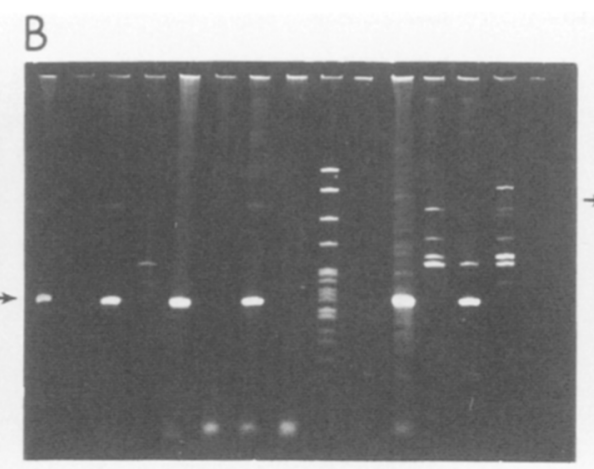

E

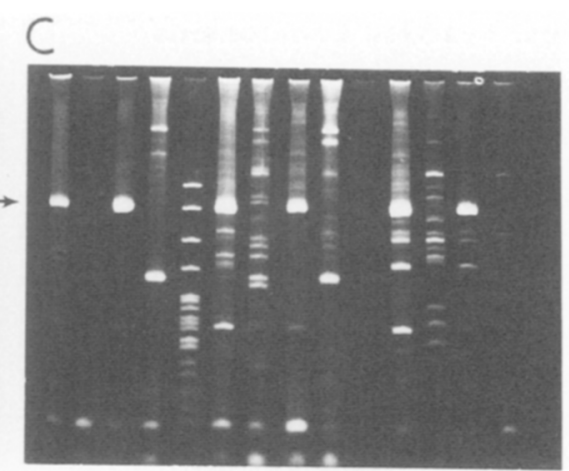

$\mathrm{F}$
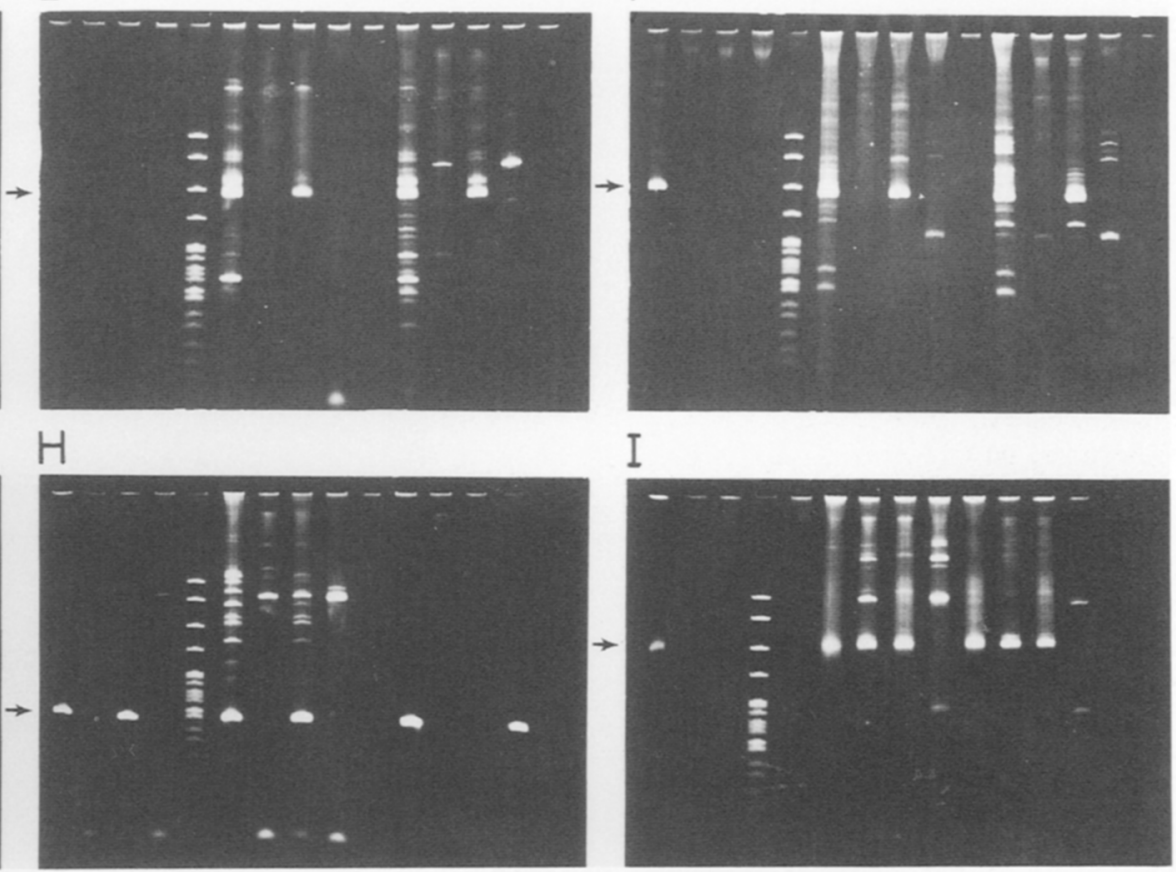

FICURE 5 TNK buffer optimizations for PCR reactions with 9 primer pairs. The optimizations shown in $A-I$ show, in each case, in the left third of the gels experiments done with TNK25, in the middle part, with TNK50, and in the rightmost part, with TNK100. PCR was done with each primer pair in the same machine for 35 cycles. The cycling conditions are described in Materials and Methods. The magnesium concentration was kept at $1.5 \mathrm{mM}$ with a total of $400 \mu \mathrm{M}$ dNTPs present at the start of the reaction. The order of lanes within a set from left to right are as follows: $50 \mathrm{ng}$ of total human DNA, 33 ng of DNA from a pool made from yeast DNA containing anonymous YACs, 33 ng from the DNA from the second lane with $5 \mathrm{ng}$ of total human DNA added, and $33 \mathrm{ng}$ of DNA from yeast strain YY 212. Molecular size marker lanes are evident in each gel. The primer pairs tested were: $(A) \mathrm{H} 19$, producing a 348-bp product; $(B)$ OTC, producing a 172-bp product; $(C)$ COS555-590, producing a 590-bp product; $(D)$ ST15, producing a 392-bp product; $(E)$ 24R, producing a 425-bp product; (F) HLA13.2, producing a 514-bp product; $(G)$ BATX, producing a 171-bp product; (H) 832.2 , producing a 138-bp product; $(I)$ VK1, producing a 420-bp product. Arrows indicate the correct product sizes.

M). These results are in accord with the results of Schildkraut and Lifson ${ }^{(6)}$ on the melting behavior of DNA. Doubling the potassium concentration will increase the DNA melting temperature by about $5^{\circ} \mathrm{C}$, with the fraction of DNA involved in melting ranging from $10 \%$ to $90 \%$ over about $7^{\circ} \mathrm{C}^{(6)}$. The underlying mechanism is the binding of potassium ions to the charged phosphate ions of the DNA backbone, the discharge of which allows the hydrogen bonding of the base to become the dominant force in double-strand formation. As a result, at potassium concentrations above $0.2 \mathrm{M}$, the PCR template-melting temperature of $94^{\circ} \mathrm{C}$ is insufficient to form singlestranded DNA, and it is clear that amplification products cannot be formed. Furthermore, oligonucleotide-DNA interactions follow the same rules, and at higher levels of $\mathrm{KCl}$, an oligonucleotide can more easily bind to DNA sites of lower affinity.

The ammonium ion, although it has the same net charge as well as a compa- rable ion radius, nevertheless behaves very differently. Relatively low levels sharply inhibit the amplification reaction. There is no obvious reason for this. It may be that the ability of ammonium ions to form hydrogen bonds is involved, perhaps interfering with the effective template concentration for successful elongation by the Taq polymerase by interacting with single-stranded DNA.

Magnesium concentration also affects both DNA-DNA and protein-DNA interactions. In particular, with several 


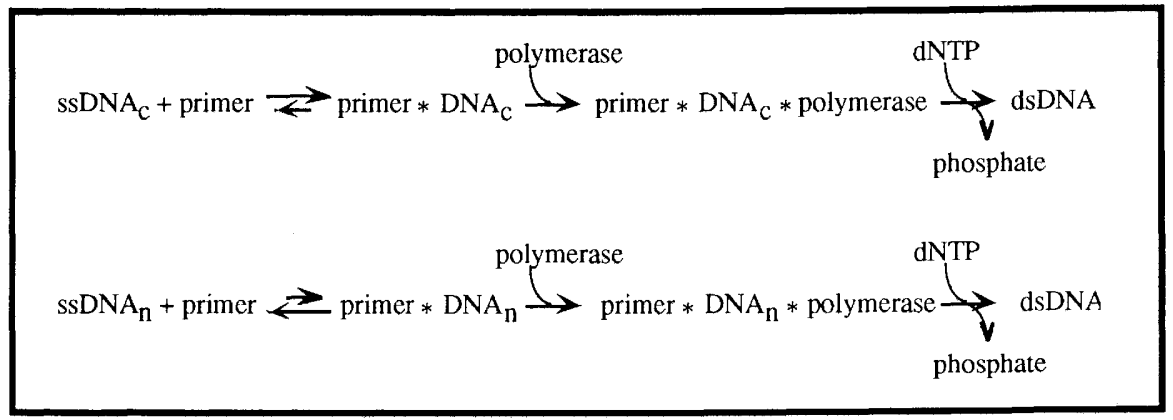

FIGURE 6 Concentration effects.

primer pairs in a series of 100 , the stringency available with the TNK100 buffer was not low enough, and raising the $\mathrm{Mg}^{2+}$ concentration proved effective.

Thus, a step-wise approach toward optimizing PCR with a newly prepared primer pair can start with a check of three TNK buffers (TNK25, TNK50, and TNK100, respectively). If higher stringency is needed, increases in annealing temperature, which would require idiosyncratic conditions for PCR, can usually be avoided by lowering the concentration of potassium (to 25, 10, and even 0 $\mathrm{mm} \mathrm{KCl}$ ), or raising the level of ammonium ions (see Fig. 3). Instead, if the first tests for optimization indicate that stringency is too high, the magnesium concentration of a TNK buffer can be raised (to 3.0 , or even $4.5 \mathrm{~mm}$ ). In the minority of instances where no satisfactory PCR outcome is seen, the primer pair is likely best discarded.

\section{Performance of the TNK Buffers}

Over time we have accumulated extensive experience with the TNK buffers. In the majority of the cases, the system has proven robust. The buffers can be easily prepared, and results gained by several laboratories with their own buffer preparations show reproducible STS-band patterns. Comparisons of several buffer batches made at intervals over 2 years have shown no significant changes with control primer pairs (data not shown). More than two-thirds of the primer-pair optimization experiments agreed with the predicted order of stringency: Buffers with the lower potassium concentration were more stringent, consistent with easier melting of the template-primer complexes. Cases of increased stringency with increased potassium concentration occur, however, and may indicate that the melting behavior of the template is somewhat different. For example, GC regions in the neighboring DNA may change the net interaction of oligonucleotides with the site of amplification. Similar considerations may apply to the less-frequent cases in which increasing $\mathrm{Mg}^{2+}$ concentration produces fewer rather than more extraneous product bands in the reactions. Any such longrange influences of DNA segments on PCR product formation are speculative; but it is already clear in several cases that the same primer pair that yields a strong PCR reaction from plasmid DNA may fail with YAC DNA containing the same target sequences at the same concentration.

In spite of the variable effects of the set of buffers on some primer pairs, the TNK system provides a way to utilize a single temperature for PCR, and thus permits the rapid optimization of assay conditions for primer pairs in an environment where thermocycler use is limiting or where a high-throughput thermocycler is in use.

\section{Next Steps Toward Automation}

A set of different annealing temperatures, a frequent approach to primer pair optimization, is complicated from the standpoint of automation, because it either demands access to several temperature-cycling machines simultaneously, each with its individual temperature set, or to solve the problem of very complex bookkeeping. The primer-pair optimization phase might also be slowed down by the need of parallel processing of the different temperature sets. The TNK buffer system has largely eliminated this problem.

With the completion of this step, the next steps toward automation of PCR are clear. Thermocyclers must provide high throughput of several hundred samples. A description of one approach can be found elsewhere. ${ }^{(7)}$ The production of several hundred PCR products rapidly leads to the next bottleneck when samples are processed in bulk. For the time being, for example, each assay is analyzed by gel electrophoresis. Automation of the complete process-selecting a DNA sample from a given DNA collection, setting up the reaction, running it, and determining the outcome-could save effort and eliminate important sources of error. YAC library screening for a specific STS sequence or screening of populations for the occurrence of a disease gene would then become a matter of machine time.

\section{ACKNOWLEDGMENTS}

We thank Drs. David Schlessinger and Maynard Olson for their constant support and discussions. This work was supported in part by National Institute of Health grant HG00201.

\section{REFERENCES}

1. Saiki, R.K., S. Scharf, F. Faloona, K.B. Mullis, G.T. Horn, H.A. Ehrlich, and N. Arnheim. 1985. Enzymatic amplification of $\beta$-globin Genomic sequences and restriction site analysis for diagnosis of sickle cell anemia. Science 230: 1350-1354.

2. Saiki, R.K., D.H. Gelfand, S. Stoffel, S.J. Scharf, R. Higuchi, G.T. Horn, K.B. Mullis, and H.A. Ehrlich. 1988. Primer-directed enzymatic amplification of DNA with a thermo-stable DNA polymerase. Science 239: 487-491.

3. Olson, M.V., L. Hood, C. Cantor, and D. Botstein. 1989. A common language for physical mapping of the human genome. Science 245: 1434-1435.

4. Schlessinger, D. 1990. Yeast artificial chromosomes: Tools for mapping and 


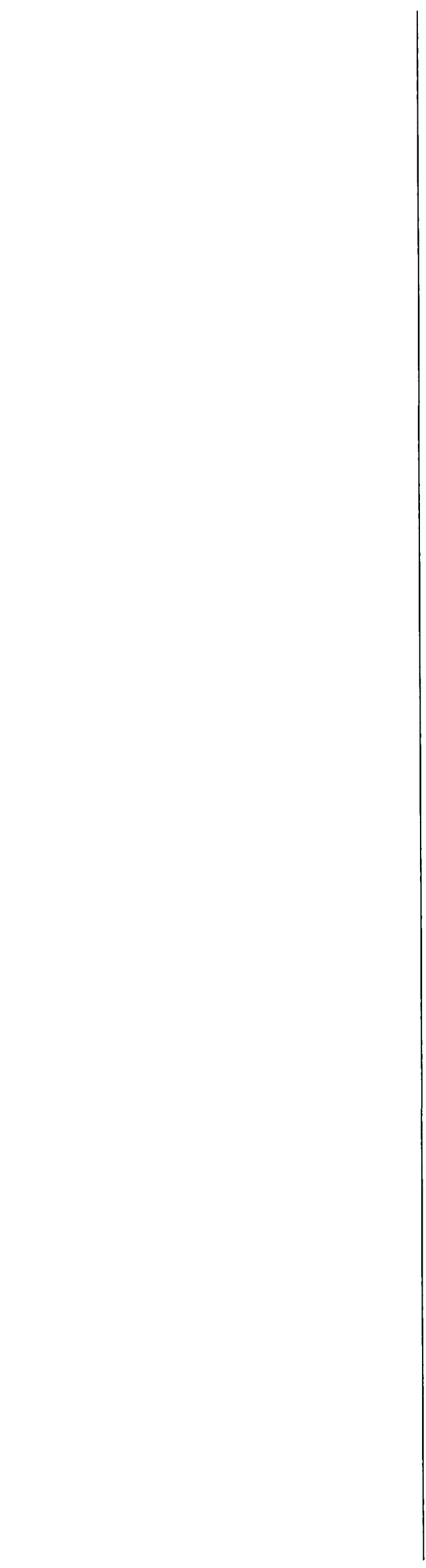




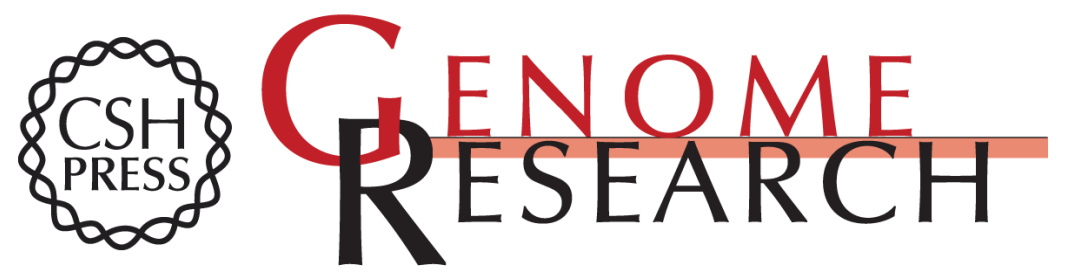

\section{PCR buffer optimization with uniform temperature regimen to facilitate automation.}

M M Blanchard, P Taillon-Miller, P Nowotny, et al.

Genome Res. 1993 2: 234-240

Access the most recent version at doi:10.1101/gr.2.3.234

References This article cites 6 articles, 3 of which can be accessed free at:

http://genome.cshlp.org/content/2/3/234.full.html\#ref-list-1

\section{License}

Email Alerting Receive free email alerts when new articles cite this article - sign up in the box at the Service top right corner of the article or click here.

\section{Affordable, Accurate Sequencing.}

To subscribe to Genome Research go to:

https://genome.cshlp.org/subscriptions 